\title{
Covered stents may provide extra protection during carotid artery stenting in high risk patients with an excessive thrombus burden
}

\author{
Ersan Tatli, ${ }^{1}$ Ahmet Barutcu, ${ }^{2}$ Emine Gazi, ${ }^{2}$ Yasemin Gunduz ${ }^{3}$
}

${ }^{1}$ Department of Cardiology, Ada Tip Hospital, Sakarya, Turkey

${ }^{2}$ Department of Cardiology, Onsekiz Mart University Hospital, Çanakkale, Turkey ${ }^{3}$ Department of Radiology, Sakarya University Hospital, Sakarya, Turkey

\section{Correspondence to} Professor Ersan Tatli, ersantatli@yahoo.com

\section{SUMMARY}

Carotid artery disease is an important cause of mortality and morbidity related to atherosclerosis. Recently, percutaneous intervention procedures have been widely used to treat atherosclerotic carotid artery disease. We report the case of a 57-year-old male patient with a history of acute amaurosis fugax. Carotid angiography was performed as blood pressure differed between his left and right arms and there was a pan-systolic murmur on the left common carotid artery. Total occlusion of the proximal right brachiocephalic artery and a thrombus occluding $90-99 \%$ of the left internal carotid artery were detected by carotid angiogram. A self-expanding graft-covered stent was successfully implanted and there were no complications. This case shows that graftcovered stents may be a good alternative technique in special situations.

\section{BACKGROUND}

Atherosclerotic carotid artery disease is one of the most important causes of cerebrovascular adverse events and in developed countries is the most common cause of mortality and morbidity after coronary artery disease and malignancy. Carotid artery stenting (CAS) is the preferred therapy. As embolism formation is the most important complication of CAS, embolism protection techniques and devices are required during the procedure. In this case report, we described an alternative approach for reducing embolism formation through the use of covered stents in a patient with severe carotid artery disease.

\section{CASE PRESENTATION}

A 57-year-old male patient presented with a history of acute amaurosis fugax. He had a history of previous myocardial infarction, diabetes mellitus and hypertension. On physical examination, his blood pressure was $70 / 40 \mathrm{~mm} \mathrm{Hg}$ in the right and 160 / $90 \mathrm{~mm} \mathrm{Hg}$ in the left arm. There was a 3/6 pansystolic murmur on the left common carotid artery.

\section{INVESTIGATIONS}

Carotid angiography demonstrated total occlusion of the proximal right brachiocephalic artery. In addition, a thrombus occluded $90-99 \%$ of the left internal carotid artery (LICA). Cerebral perfusion was totally dependent on the left carotid artery system (figures 1 and 2). LICA stenting was the chosen therapy but brain perfusion needed to be protected. The right common carotid artery occlusion meant a proximal blocking-based protection system could not be used as there was a high probability of embolism formation from the thrombus on the blocking lesion.

\section{TREATMENT}

We decided to place a graft-covered stent through the lesion first, and contain the plaque and thrombus between the stent and the lumen. Therefore, a graft covered stent $(5 \times 13$, Direct $)$ was implanted with $12 \mathrm{~atm}$ pressure. After removing the distal blockingbased protection system, we opened the selfexpanding stent $(7 \times 10 \times 30$, Cristallo) (figure 3$)$ and dilated the stent using a post-dilatation balloon

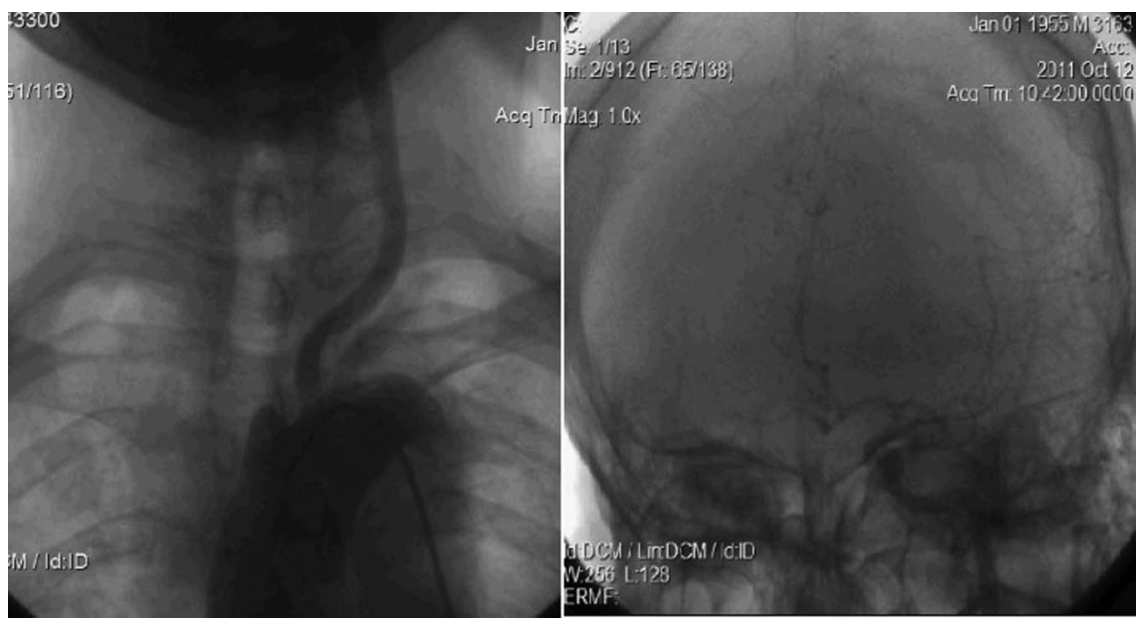

Figure 1 Carotid angiogram shows total occlusion of the right brachiocephalic artery and cranial perfusion. 


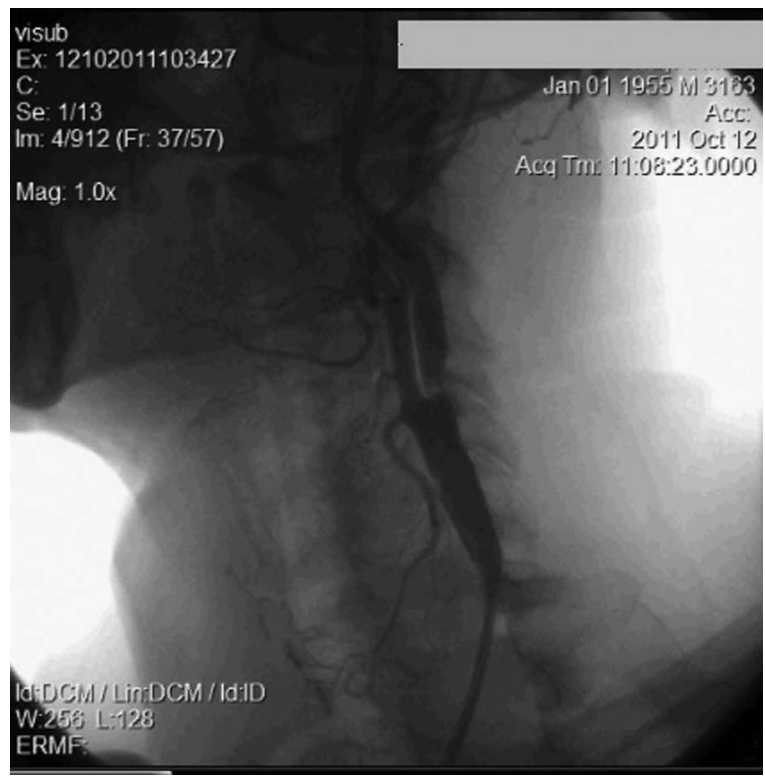

Figure 2 Left carotid angiogram shows a thrombus in the left internal carotid artery.
$(5 \times 20$, Tarcomgrande). The procedure was completed successfully and there were no complications (figure 4).

\section{OUTCOME AND FOLLOW-UP}

Control Doppler ultrasonography examinations at 1 and 6 months after the procedure showed no evidence of restenosis nor were there any clinical sign of restenosis.

\section{DISCUSSION}

CAS is used frequently for the treatment of carotid artery stenosis. $^{1}{ }^{2}$ Most CAS-related complications occur as a result of embolism formation. The most embologenic phases of the CAS procedure are the pre-dilatation, stent deployment and postdilatation stages. ${ }^{3}$ The use of protection devices has been associated with a reduced rate of neurological complications ${ }^{4}$ but may actually increase the number of emboli and cannot prevent post-procedural embolism formation. ${ }^{5}$

An alternative approach to reducing embolisms may be through the use of covered stents. A covered stent, in which the stent mesh is coated with a thin membrane, may prevent the passage of atherosclerotic material through the stent grid. We have proposed that covered stents efficiently reduce embolism formation during stent deployment, post-dilatation and post-procedurally.

Graft-covered stents contain the atherosclerotic and embolic materials between the vessel wall and the stent itself, thus

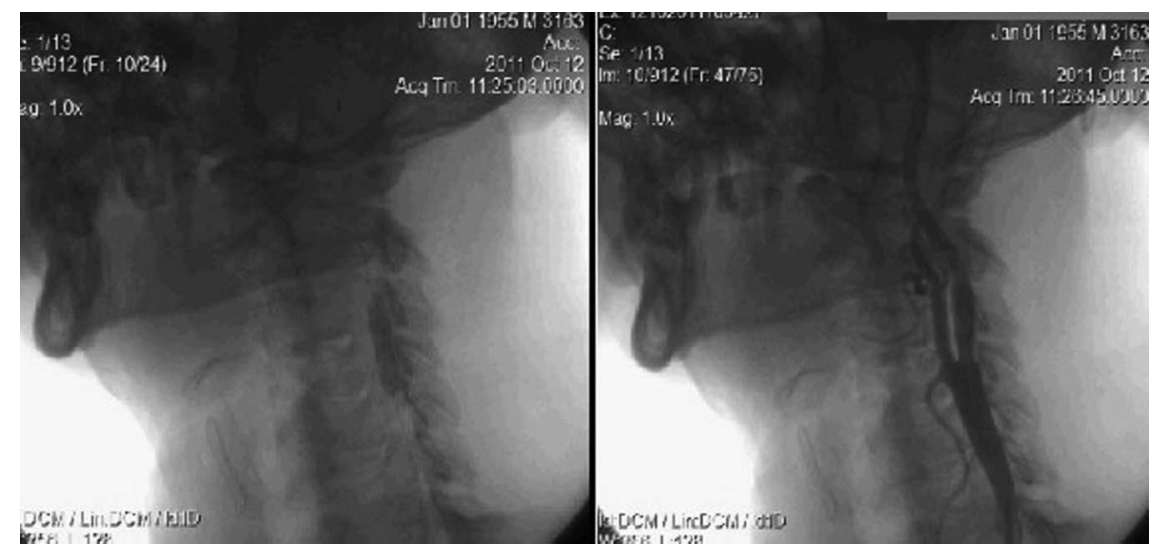

Figure 3 Stenting of the left internal carotid artery with a graft-covered stent.
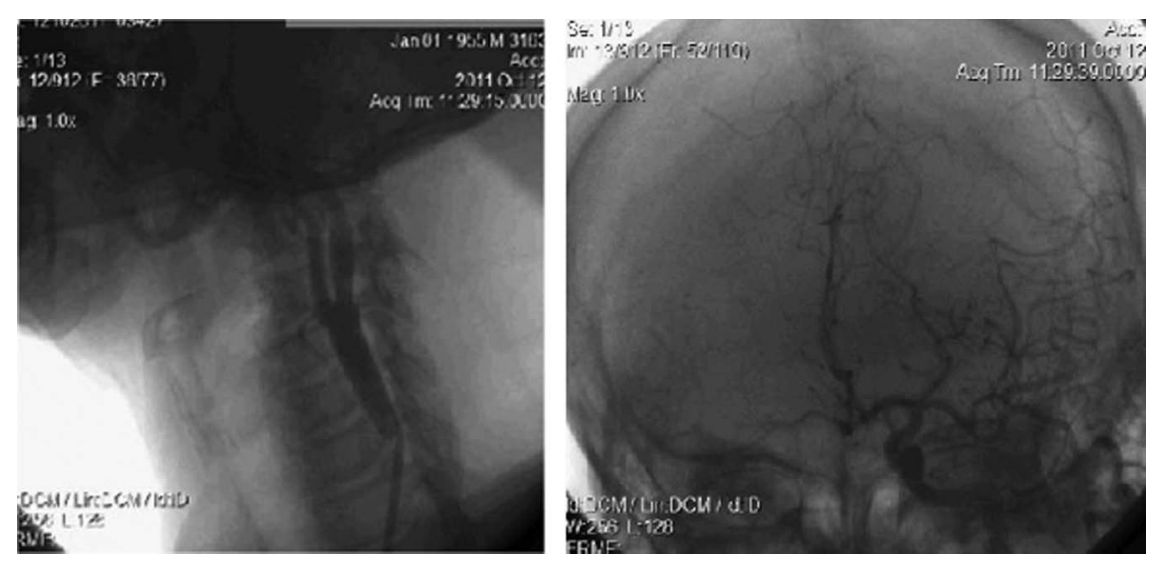

Figure 4 Left carotid angiogram shows no residual stenosis after stenting. 
reducing embolic events. Schillinger et $a l^{6}$ followed 14 patients with carotid stenosis for 6 months. Graft-covered stents had been implanted in eight of these patients and bare stents in six. There were fewer embolic events during and after the procedure in the graft-covered than the bare stent group, but restenosis was observed in three of the patients in the graft-covered stent group. Cil et $a l^{7}$ employed graft-covered stents in three patients with carotid artery stenosis without the use of protection devices; no restenosis was observed at 6-month follow-up. In contrast to the cases described in the literature, we used a selfexpanding graft-covered stent.

Our experience indicates that graft-covered stents may be a good option when a proximal filter blocking system cannot be used due to the tortuous structure of the vessel.

\section{Learning points}

- Carotid artery stenting is the preferred treatment for atherosclerotic carotid artery disease but may result in embolism formation.

- The use of protection devices has been associated with a reduced rate of neurological complications but they do not prevent post-procedural embolism formation.

- Graft-covered stents may reduce embolic events and are a good alternative technique to prevent embolism formation.
Competing interests None.

Patient consent Obtained.

Provenance and peer review Not commissioned; externally peer reviewed.

\section{REFERENCES}

1 Roubin GS, New G, lyer SS, et al. Immediate and late clinical outcomes of carotid artery stenting in patients with symptomatic and asymptomatic carotid artery stenosis: a 5-year prospective analysis. Circulation 2001;103:532-7.

2 Ederle J, Dobson J, Featherstone RL, et al. Carotid artery stenting compared with endarterectomy in patients with symptomatic carotid stenosis (International Carotid Stenting Study): an interim analysis of a randomised controlled trial. Lancet 2010;375:985-97.

3 Theron J, Guimaraens L, Coskun 0, et al. Complications of carotid angioplasty and stenting. Neurosurg Focus 1998;5:1-19.

4 Terada T, Tsuura M, Matsumoto $\mathrm{H}$, et al. Results of endovascular treatment of internal carotid artery stenoses with a newly developed balloon protection catheter. Neurosurgery 2003;53:617-23.

5 Schlüter M, Tübler T, Mathey DG, et al. Feasibility and efficacy of balloon-based neuroprotection during carotid artery stenting in a single-center setting. I Am Coll Cardiol 2002;40:890-5.

6 Schillinger M, Dick P, Wiest $G$, et al. Covered versus bare self-expanding stents for endovascular treatment of carotid artery stenosis: a stopped randomized trial. Endovasc Ther 2006;13:312-19.

7 Cil BE, Akpinar E, Peynircioglu B, et al. Utility of covered stents for extracranial internal carotid artery stenosis. AJNR Am J Neuroradiol 2004;25:1168-71.

Copyright 2013 BMJ Publishing Group. All rights reserved. For permission to reuse any of this content visit http://group.bmj.com/group/rights-licensing/permissions.

BMJ Case Report Fellows may re-use this article for personal use and teaching without any further permission.

Become a Fellow of BMJ Case Reports today and you can:

- Submit as many cases as you like

- Enjoy fast sympathetic peer review and rapid publication of accepted articles

- Access all the published articles

- Re-use any of the published material for personal use and teaching without further permission

For information on Institutional Fellowships contact consortiasales@bmjgroup.com

Visit casereports.bmj.com for more articles like this and to become a Fellow 